SCIENTIFIC REPORT

\title{
Do selective topical $\beta$ antagonists for glaucoma have respiratory side effects?
}

\section{J F Kirwan, J A Nightingale, C Bunce, R Wormald}

Br J Ophthalmol 2004;88:196-198. doi: 10.1136/bjo.2003.017715

Background/aims: Topical $\beta$ antagonists are prescribed for glaucoma in approximately 500000 people in the United Kingdom. The authors have previously shown that topical $\beta$ antagonists are associated with an excess incidence of airways obstruction. They examined whether selective topical $\beta$ antagonists are associated with excess airways obstruction. Methods: A historical cohort study was performed to determine the incidence of airways obstruction in subjects with no previous history of airways obstruction, following treatment with topical $\beta$ antagonists for glaucoma for the period 1993-7. Cases were defined as having received a first prescription of a drug specifically used in the management of airways obstruction.

Results: For selective topical $\beta$ antagonists 12 of 324 treated subjects developed airways obstruction, compared with 112 of 9094 controls (adjusted hazard rate 3.0 (95\% confidence interval $(95 \% \mathrm{Cl}) 1.6$ to 5.4$))$. For non-selective topical $\beta$ antagonists, the corresponding figures were 69 of 2321 subjects compared with the same control group (adjusted hazard rate 2.2 (1.6 to 3.0)). There was no significant difference between groups $\left(p=0.47, \chi^{2}\right)$, both being associated with a significantly increased risk of airways obstruction.

Conclusion: Selective topical $\beta$ antagonists do appear to have an excess risk of airways obstruction in this population setting and should be subject to the same prescribing caveats as unselective topical $\beta$ antagonists.

G laucoma and ocular hypertension affect approximately one in 25 of people over the age of $40 .{ }^{1-4}$ The most commonly prescribed glaucoma drugs in the United Kingdom are topical $\beta$ antagonists. These reduce aqueous secretion and lower intraocular pressure (IOP) and reduce the progression of glaucomatous visual field loss. ${ }^{56}$ Topical $\beta$ antagonists are generally well tolerated. However, these drugs may enter the systemic circulation and produce bronchospasm. Hence, topical $\beta$ antagonists are contraindicated in patients with a history of airways obstruction. ${ }^{7}$ We have previously shown that use of topical $\beta$ antagonists is associated with an increased incidence of airways obstruction in individuals with no previous history of respiratory disease. ${ }^{8}$ Selective topical $\beta$ antagonists are considered to be less likely to cause bronchospasm and some workers have suggested that their use may be acceptable in patients with airways obstruction. ${ }^{9}$ A recent systematic review has shown that selective $\beta$ antagonists are not associated with respiratory side effects when used for cardiovascular disease. ${ }^{10}{ }^{11}$ The aim of this study was to explore whether selective topical $\beta$ antagonists were associated with a lower incidence of new airways obstruction than their non-selective counterparts in a population setting.

\section{METHODS}

The Mediplus UK primary care database was used to identify subjects using selective and non-selective ophthalmic topical $\beta$ antagonists for the first time from 1 January 1993 to 31 December 1997. This database contains anonymised general practice records. ${ }^{12}{ }^{13}$ During this period, 904653 patients were "active" (active patients are those who were alive and available for the prescription of a drug or a GP consultation up to the end of the study) in the database.

The study was based on a historical cohort. Patients receiving treatment with topical $\beta$ antagonists were followed from their first GP prescription to l December 1999, to identify those who developed airways obstruction. When a subject was identified in the database as having received a prescription for a topical $\beta$ antagonist, unexposed subjects were selected at random (up to a maximum of four, loosely matched for age). Patients over 30 years of age with no previous diagnosis of airways obstruction or prescription of drugs for the treatment of airways obstruction were included. Validation was performed by inspection of a random sample of 50 full longitudinal records, all of which agreed with the summarised data.

Subjects were considered to have developed airways obstruction when a prescription of a drug used for the management of airways obstruction was instigated (inhaled or oral $\beta_{2}$ agonists, inhaled corticosteroids, theophyllines, and inhaled anti-cholinergics). Incidence rate ratios of disease were calculated, with 95\% confidence intervals, at one year. Adjusted analysis was performed using a proportional hazards model with age, sex, use of systemic $\beta$ antagonists, use of non-steroidal anti-inflammatory drugs, use of nitrates, smoking, season of presentation, and number of visits to GP after index date as covariates. (Stata Statistical Software 7.0, Stata Corporation, College Station, TX, USA).

\section{RESULTS}

From the database, 3358 subjects who had received a first prescription of topical $\beta$ antagonists during the study period and remained under surveillance for a minimum of 2 years were enumerated (group TBA-A) and 12258 unexposed subjects (group C). Of the enumerated subjects, 477 had received a selective topical $\beta$ antagonist (group TBA-S) and 2881 had received an unselective agent (group TBA-U).

Previous history of airways obstruction was present in 153 of group TBA-S (32.1\%), 560 of group TBA-U (19.4\%), and 1303 of group C $(25.8 \%)$. Thus, there were 324,2321 , and 9091 subjects with no previous history of airways obstruction for analysis.

Details of subjects in the three groups are shown in table 1. Exposed subjects were slightly older than unexposed subjects (68.6 $v 67.5$ years), less likely to smoke and to have used systemic $\beta$ antagonists in the previous 12 months. Patients in the TBA-S group were very similar to the TBA-U group.

Incidence rate ratio data are shown in table 2 . Incident airways obstruction was diagnosed in 12 of 324 TBA-S 
Table 1 Characteristics of subjects and controls

\begin{tabular}{|c|c|c|c|c|}
\hline & & $\begin{array}{l}\text { Control } \\
(n=9091)\end{array}$ & $\begin{array}{l}\text { TBA-U } \\
(n=2321)\end{array}$ & $\begin{array}{l}\text { TBA-S } \\
(n=324)\end{array}$ \\
\hline Mean age (years) (SD) & & $67.54(11.5)$ & $68.54(11.88)$ & $68.73(12.48)$ \\
\hline \multirow[t]{2}{*}{ Patient sex } & $\mathrm{F}$ & $4671(51.4 \%)$ & 1204 (51.9\%) & $156(48.1 \%)$ \\
\hline & M & $4423(48.6 \%)$ & $1117(48.1 \%)$ & $168(51.9 \%)$ \\
\hline Systemic $\beta$ antagonists in previous & No & $8106(89.1 \%)$ & $2140(92.2 \%)$ & $298(92.0 \%)$ \\
\hline 12 months & Yes & $988(10.9 \%)$ & $181^{* *}(7.8 \%)$ & $26(8.0 \%)$ \\
\hline \multirow[t]{2}{*}{ NSAID in previous 12 months $\dagger$} & No & $7212(79.3 \%)$ & $1836(79.1 \%)$ & $249(76.9 \%)$ \\
\hline & Yes & $1882(20.7 \%)$ & $485(20.9 \%)$ & $75(23.1 \%)$ \\
\hline \multirow[t]{2}{*}{ Nitrates prescribed } & No & $8786(96.6 \%)$ & $2249(96.9 \%)$ & $315(97.2 \%)$ \\
\hline & Yes & $308(3.4 \%)$ & $72(3.1 \%)$ & $9(2.8 \%)$ \\
\hline \multirow{2}{*}{ Smoker } & No & $7568(83.2 \%)$ & $2006(86.4 \%)$ & $271(83.6 \%)$ \\
\hline & Yes & $1526(16.8 \%)$ & $315^{* *}(13.6 \%)$ & $53(16.4 \%)$ \\
\hline \multirow{2}{*}{$\begin{array}{l}\text { GP consultations in the year before } \\
\text { index date }\end{array}$} & Mean & 8.0 & 10.2 & 11.5 \\
\hline & Median & 5.0 & $7.0^{* *}$ & $9.0^{* *}$ \\
\hline \multicolumn{5}{|c|}{$\begin{array}{l}\text { TBA-U = unselective topical } \beta \text { antagonist treated subjects; TBA-S = selective topical } \beta \text { antagonist treated subjects. } \\
p \text { Values calculated using } \chi^{2} \text { test or Mann-Whitney test. }{ }^{*} p<0.01 \text { ( } p \text { values are in comparison with the unexposed } \\
\text { cohort); }{ }^{* *} p<0.001 \text {. } \\
\text { †NSAID = non-steroidal anti-inflammatory drugs. }\end{array}$} \\
\hline
\end{tabular}

subjects $(3.7 \%), 69$ of 2321 TBA-U subjects $(3.0 \%)$, and 112 of $9094(1.2 \%)$ subjects from group C. Both TBA-S and TBA-U subjects had a significantly higher incidence of airways obstruction (odds ratios 3.1 and 2.5 respectively $(\mathrm{p}<0.001)$ ) than group $\mathrm{C}$, but not significantly different from each other $\left(\mathrm{p}=0.47\left(\chi^{2}\right)\right)$.

Results of proportional hazard modelling showed very similar results, with a hazard ratio of 2.96 for TBA-S and 2.22 for TBA-U.

\section{DISCUSSION}

This study suggests that selective topical $\beta$ antagonists are associated with an increased risk of airways obstruction in individuals with no previous respiratory history. Furthermore, the magnitude of risk appears similar to that for unselective topical $\beta$ antagonists. There were insufficient numbers to detect a difference between selective and unselective topical $\beta$ antagonists in this study. The study had only $40 \%$ power to detect a $50 \%$ difference in risk between selective and unselective topical $\beta$ antagonists, but had over $80 \%$ power to detect a relative risk of two or more for selective topical $\beta$ antagonists compared to the control group. These data refute smaller, intervention studies that have suggested that selective topical $\beta$ antagonists for glaucoma are less likely to have respiratory side effects. Early intervention studies reported that betaxolol (the only commercially available selective topical $\beta$ antagonist) did not affect spirometry. ${ }^{14-16}$ However, these studies had limited power and used highly selected patient groups. ${ }^{17}$ Severe adverse respiratory effects with betaxolol are well described, in both asthmatics and those without a history of respiratory disease. ${ }^{18}$ Weinreb et al reported that betaxolol was well tolerated by most subjects with a known history of chronic obstructive pulmonary disease; however 5\% withdrew because of respiratory symptoms. Diggory et al showed improvements in spirometry in subjects switched from an unselective topical $\beta$ antagonist (timolol) to betaxolol, although a greater improvement appeared to be evident in subjects switched to another antiglaucoma drug. ${ }^{19}$ We were interested to examine whether these differences meant that selective agents might be safer than unselective agents in a population setting. The effects considered here pertain to those with no previous history of airways obstruction.

There are several possible limitations of this study. This type of study depends on patients reporting to their GP and the GP making a diagnosis. This may underestimate the prevalence of airways obstruction. Although inhaled corticosteroids may be used in other conditions such as bronchiectasis, their use in these conditions is far less common than their use in asthma and COPD. Reporting bias is also a possibility, although we consider this to be relatively unlikely as a diagnosis of "glaucoma" is not generally associated with "asthma" or "COPD." In any study such as this there is a potential for confounding and it could be argued that the observed effect of selective topical $\beta$ antagonists was due to residual confounding - that is, that those individuals prescribed selective drugs were had a degree of respiratory disease sufficient to affect prescribing but not registered on the database. This is unlikely for two reasons. Firstly, we used a broad definition of prior airways obstruction so that patients with "soft" respiratory symptoms would be excluded and combined this with a more demanding definition of incident airways obstruction requiring a prescription. Secondly, such an effect would only have affected part of the population prescribed a selective topical $\beta$ antagonist as they are also used widely as first line drugs of those prescribed an unselective agent for the first time, $14.4 \%$ had some previous record of airways obstruction compared to $20.6 \%$ of those prescribed a selective agent. Although this is a statistically significant difference, the magnitude of the

Table 2 Risk of subjects developing new airways obstruction following treatment with unselective and selective topical $\beta$ antagonist compared to controls

\begin{tabular}{lllll}
\hline & $\begin{array}{l}\text { Number of new } \\
\text { TBA cases }\end{array}$ & $\begin{array}{l}\text { Number of unexposed } \\
\text { subjects (group C) }\end{array}$ & Unadjusted rate ratio (95\% Cl) & Adjusted hazard ratio (95\% Cl) \\
\hline $\begin{array}{l}\text { TBA-U treated } \\
\text { subjects } \\
\begin{array}{l}\text { TBA-S treated } \\
\text { subjects }\end{array}\end{array}$ & $69 / 2321(3.0 \%)$ & $112 / 9094(1.2 \%)$ & $2.30^{* *}(1.69$ to 3.12$)$ & $2.22^{* *}(1.63$ to 3.02$)$ \\
\hline
\end{tabular}

TBA- $U=$ unselective topical $\beta$ antagonist treated subjects; TBA-S = selective topical $\beta$ antagonist treated subjects.

${ }^{*} \mathrm{p}<0.01 ;{ }^{* *} \mathrm{p}<0.001$ 
difference is not very large and the majority of cases had no previous respiratory history. Other confounding effects are also unlikely; apart from IOP and age, the major risk factors for glaucoma are ethnicity and family history of glaucoma. Airways obstruction in the older age group does not have a strong recognised ethnic bias. An inherent weakness in this type of study is that clinical data may not be thoroughly validated. However for prescribing information, the database is likely to be sound and systematic error is unlikely to account for our findings.

In summary, these data suggest that selective topical $\beta$ antagonists do have respiratory side effects in a population setting and therefore their prescription for glaucoma and ocular hypertension should be subject to the same caveats as all topical $\beta$ antagonists.

\section{ACKNOWLEDGEMENT}

We thank Wellcome Trust, IGA.

\section{Authors' affiliations \\ J F Kirwan, Institute of Ophthalmology, London, UK \\ J F Kirwan, C Bunce, R Wormald, Moorfields Eye Hospital, London, UK J A Nightingale, Department of Respiratory Medicine, Hammersmith Hospital, London, UK}

Correspondence to: James F Kirwan, Department of Epidemiology and International Eye Health, Institute of Ophthalmology, 1 1-43 Bath Street, London ECIV 9EL, UK; ifkirwan@ucl.ac.uk

Accepted for publication 5 March 2003

\section{REFERENCES}

1 Mitchell P, Smith W, Attebo W, et al. Prevalence of open-angle glaucoma in Australia. The Blue Mountains Eye Study. Ophthalmology 1996;103:1661-9.

2 Dielemans I, Vingerling JR, Wolfs RC, et al. The prevalence of primary openangle glaucoma in a population-based study in the Netherlands. The Rotterdam Study. Ophthalmology 1994;101:1851-5.
3 Tielsch JM, Katz J, Quigley HA, et al. Diabetes, intraocular pressure, and primary open-angle glaucoma in the Baltimore Eye Survey. Ophthalmology 1995; 102:48-53.

4 Tielsch JM, Sommer A, Katz J, et al. Racial variations in the prevalence of primary open-angle glaucoma. The Baltimore Eye Survey. JAMA 1991;266:369-74.

5 Kass MA, Hever DK, Higginbotham EJ, et al. The ocular hypertension treatment study: a randomized trial determines that topical ocular hypotensive medication delays or prevents the onset of primary open-angle glaucoma. Arch Ophthalmol 2002;120:701-13.

6 Heiil A, Leske MC, Bengtsson B, et al. Reduction of intraocular pressure and glaucoma progression: results from the Early Manifest Glaucoma Trial. Arch Ophthalmol 2002;120:1268-79.

7 BMA \& RPS. British National Formulary. London: British Medical Association and Royal Pharmaceutical Society of Great Britain, 1998.

8 Kirwan JF, Nightingale JA, Bunce C, et al. Beta blockers for glaucoma and excess risk of airways obstruction: population based cohort study. BMJ 2002;325:1396-7.

9 Weinreb RN, van Buskirk EM, Cherniack R, et al. Long-term betaxolol therapy in glaucoma patients with pulmonary disease. Am J Ophthalmol 1988;106:162-7.

10 Salpeter SR, Ormiston TM, Salpeter EE. Cardioselective $\beta$-blockers in patients with reactive airway disease: a meta-analysis. Ann Intern Med 2002;137:715-25

11 Salpeter SS, Ormiston T, Salpeter E, et al. Cardioselective $\beta$-blockers for chronic obstructive pulmonary disease. Cochrane Database Syst Rev 2002:CD003566.

12 IMS Health. Quality, validity, representativeness and completeness of data. London: IMS, 1999

13 Lawrenson RA, Coles G, Walton K, et al. Characteristics of practices contributing to the Mediplus database and the implications for its use in epidemiological research. J Infomatics Prim Care 1998:14-18.

14 Dunn TL, Gerber MJ, Shen AS, et al. The effect of topical ophthalmic instillation of timolol and betaxolol on lung function in asthmatic subjects. Am Rev Respir Dis 1986; 133:264-8.

15 Schoene RB, Abuan T, Ward RL, et al. Effects of topical betaxolol, timolol, and placebo on pulmonary function in asthmatic bronchitis. Am J Ophthalmol 1984;97:86-92.

16 Van Buskirk EM, Weinreb RN, Berry DP, et al. Betaxolol in patients with glaucoma and asthma. Am J Ophthalmol 1986;101:531-4.

17 Spiritus EM. Casciari R. Effects of topical betaxolol, timolol, and placebo on pulmonary function in asthmatic bronchitis [letter]. Am J Ophthalmol 1985; 100:492-4.

18 Harris LS, Greenstein SH, Bloom AF. Respiratory difficulties with betaxolol Am J Ophthalmol 1986;102:274-5.

19 Diggory P, Cassels-Brown A, Vail A, et al. Avoiding unsuspected respiratory side-effects of topical timolol with cardioselective or sympathomimetic agents. Lancet 1995;345:1604-6.

\section{$\mathrm{ECHO}$}

\section{Oral pilocarpine for Sjögren's syndrome}

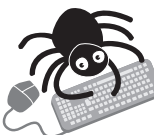

Please visit the British Journal of Ophthalmology website [www. bjophthalmol. com] for a link to the full text of this article. jögren's syndrome is an autoimmune disease that affects exocrine glands and causes

keratoconjunctivitis sicca. Ocular complications include corneal ulceration, episcleritis, keratitis, and bacterial or viral infection. The use of artificial tears is the mainstay of treatment. It has been suggested that pilocarpine, a cholinergic parasympatheticomimetic agonist, might improve the symptoms of keratoconjunctivitis sicca. Researchers in Greece have used oral pilocarpine with good effect.

Eighty five women (mean age 58 years) with Sjögren's syndrome were randomised to 12 weeks treatment with oral pilocarpine $5 \mathrm{mg}$ twice daily plus artificial tears, artificial tears only, or occlusion of the inferior lachrymal puncta plus artificial tears. Changes in symptoms were assessed on a $100 \mathrm{~mm}$ visual analogue scale (VAS). Symptom improvement was $90 \%$ (pilocarpine) $v 30 \%$ (artificial tears only), $v 60 \%$ (punctal occlusion). Improvement with pilocarpine was significantly better than with punctal occlusion $(\mathrm{p}<0.05)$ and highly significantly better than with artificial tears alone $(p<0.001)$. With the rose bengal test improvement was significantly greater in the pilocarpine group than in the other two groups but there were no significant differences between groups with Schirmer's-I test. Four of 29 patients on pilocarpine complained of headache and three of those also complained of nausea, vomiting, and sweating. No patient withdrew from the study because of adverse effects of pilocarpine.

Oral pilocarpine may give symptomatic relief for patients with Sjögren's syndrome.

A Annals of the Rheumatic Diseases 2003;62:1204-1207. 